\title{
Acute pulmoner embolism mimicking acute coronary syndrome
}

\author{
Fulya Avcı Demir ${ }^{\mathrm{a}, *}$, Yunus Okudan ${ }^{\mathrm{b}}$, Ahmet Altınbaş ${ }^{\mathrm{b}}$ \\ a Department of Cardiology, Isparta State Hospital, Isparta, Turkey \\ b Department of Cardiology, Süleyman Demirel University, Isparta, Turkey
}

\section{A R T I C L E I N F O}

\section{Article history:}

Received 31 May 2016

Received in revised form 28 February 2017

Accepted 8 May 2017

Available online 9 August 2017

\begin{abstract}
A B S T R A C T
Clinical and electocardiographic (ECG) features in pulmonary embolism (PE) lack of specificity and may mimic an acute coronary syndrom (ACS). We here report a case of a 56-year-old woman presenting with chest pain secondary to pulmonary artery embolism which was initially diagnosed as ACS due to electrocardiographic changes and raised troponin. PE presenting with negative T-wave inversion can mimic ACS and misdirect the diagnostic approach. Simultaneous T-wave inversions in anterior and inferior leads are important clues suggesting PE. Most common ECG findings in PE are anteroseptal T-wave inversion/ST-elevation or depression along with complete or incomplete right bundle branch block, sinus tachycardia, low QRS-complex voltage, an S1Q3T3 pattern, and right axis deviation. The reasons for the ECG changes that seem like ischemia are sudden RV strain, hypoxemia and the release of catecholamines. So we have to be aware that PE can present as acute coronary syndrome with ECG changes preoccupy ischemia

(C) 2016 The Society of Cardiovascular Academy. Production and hosting by Elsevier B.V. This is an open access article under the CC BY-NC-ND license (http://creativecommons.org/licenses/by-nc-nd/4.0/).
\end{abstract}

\section{Introduction}

Clinical and electocardiographic (ECG) features in pulmonary embolism (PE) lack of specificity and may mimic an acute coronary syndrom (ACS). We here report a case of a 56-year-old woman presenting with chest pain secondary to pulmonary artery embolism which was initially diagnosed as ACS due to electrocardiographic changes and raised troponin.

\section{Case}

A 56-year-old diabetic, hypertensive, obese woman with a history of smoking was admitted to the emergency service with chest pain and nausea. She did not have any other relevant symptoms. Clinically, she was oriented, her cardiovascular and chest examination was unremarkable. Her pulse was regular at 93 beats/min, blood pressure was 142/ $89 \mathrm{~mm} \mathrm{Hg}$ and respiratory rate was 18 breaths/min. The room air oxygen saturation was 99\%. In her blood investigations everything was normal except troponin I which was $0.98 \mathrm{ng} / \mathrm{ml}$ (normal $<0.06 \mathrm{ng} / \mathrm{ml}$ ). On her 12 lead ECG, the rhythm was sinus. There was ST segment depression in leads V3-V6 and T wave inversion in anterior and inferior leads and minimal ST segment elevation in AVR (Fig. 1). She was diagnosed as non-ST elevation myocardial infarction and referred to a third step hospital for diagnosis and treatment. Cause of her insistent chest pain invasive coronary evaluation planned. The coronary

\footnotetext{
* Corresponding author.

E-mail address: fulyaavcidemiğr@gmail.com (F.A. Demir).

Peer review under responsibility of The Society of Cardiovascular Academy.
}

angiography revealed normal. Transthoracic echocardiography demonstrated good left ventricular systolic function but a dilated right ventricle (RV). There was mild tricuspid regurgitation with calculated RV systolic pressure of $45 \mathrm{~mm} \mathrm{Hg}$. So thoracic computed tomographic angiogram planned and it showed extensive PE of both right and left main pulmonary arteries extending distally into lobar, segmental and sub segmental branches (Fig. 2). A Doppler scan of the legs revealed no deep vein thrombosis. Her thrombophilia profile was normal. The

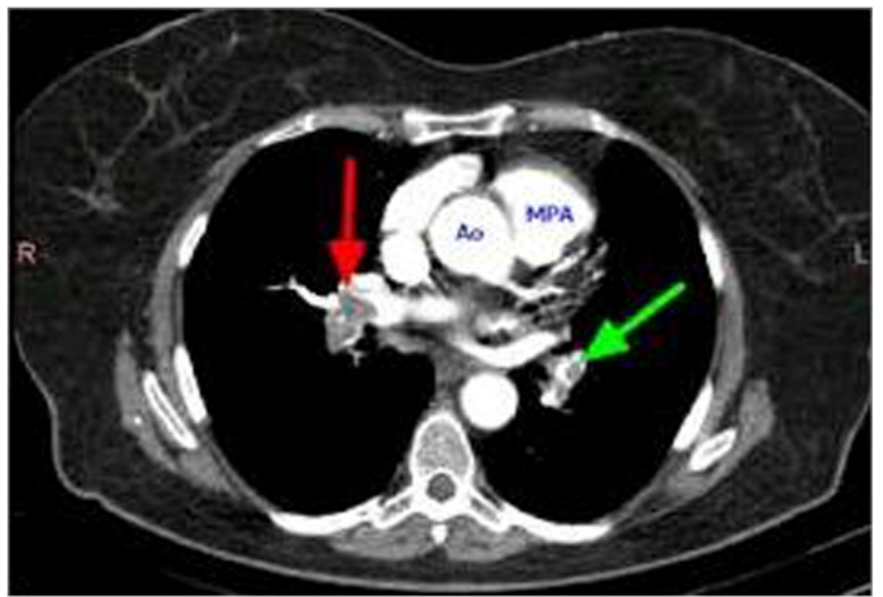

Fig. 1. Patient s 12 lead electrocardiogram on admission. 


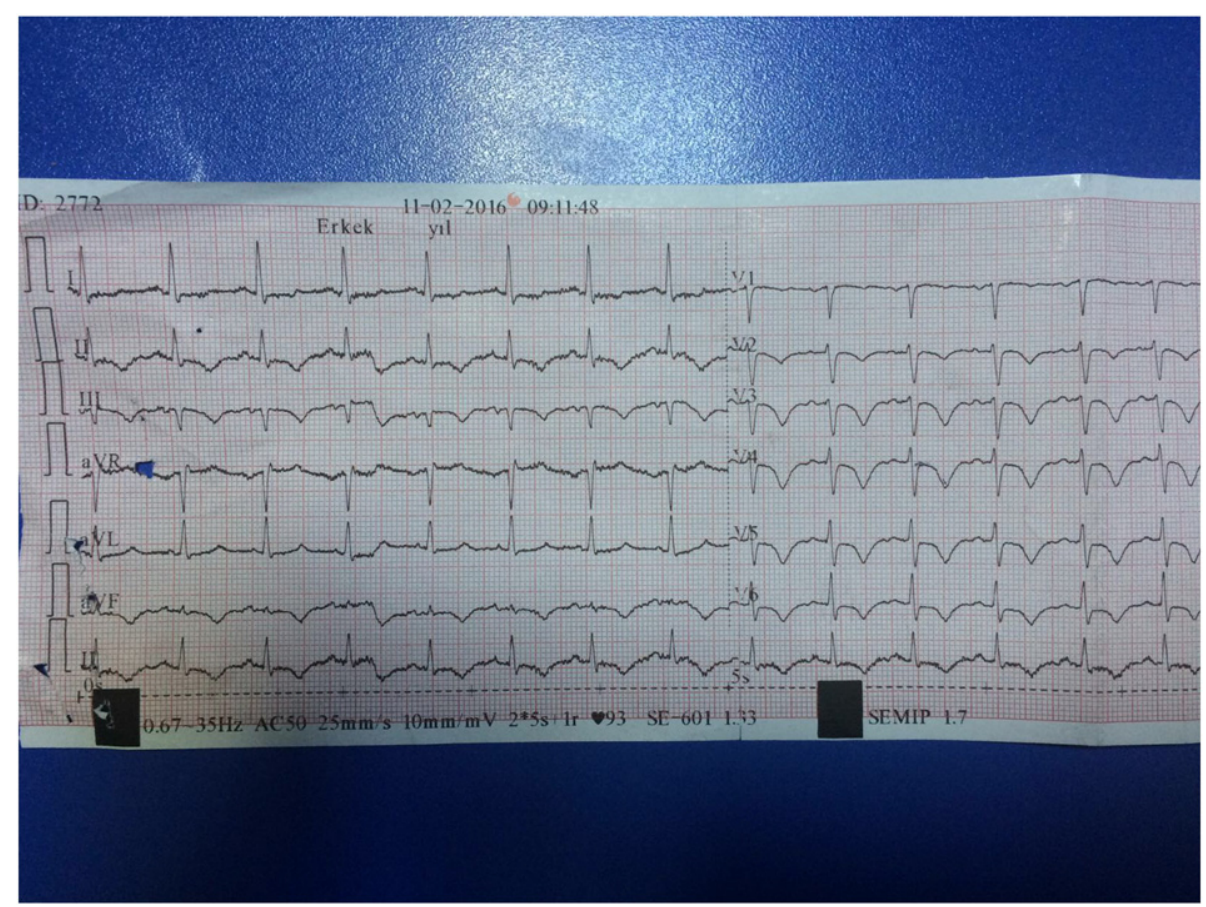

Fig. 2. Pulmoner embolism seen on pulmoner CT angiogram.

patient was treated with low molecular weight heparin (LMWH) along with overlap warfarin.

\section{Conclusion}

PE presenting with negative T-wave inversion can mimic ACS and misdirect the diagnostic approach. Simultaneous T-wave inversions in anterior and inferior leads are important clues suggesting PE. Most common ECG findings in PE are anteroseptal T-wave inversion/ST-elevation or depression along with complete or incomplete right bundle branch block, sinus tachycardia, low QRS-complex voltage, an S1Q3T3 pattern, and right axis deviation. The reasons for the ECG changes that seem like ischemia are sudden RV strain, hypoxemia and the release of catecholamines. In our case, patients' oxygen saturation was normal so we don't expect a catecholamine surge which is generally induced by severe hypoxemia. We think sudden pressure load on a noncompensatory right ventricle and global or focal ischemia induced by this additional strain may be the reason of the ECG changes. As a result, we have to be aware that PE can present as acute coronary syndrome with ECG changes preoccupy ischemia. Otherwise, the diagnosis of PE can be easily missed and patients may not receive appropriate treatment resulting in increased mortality. 